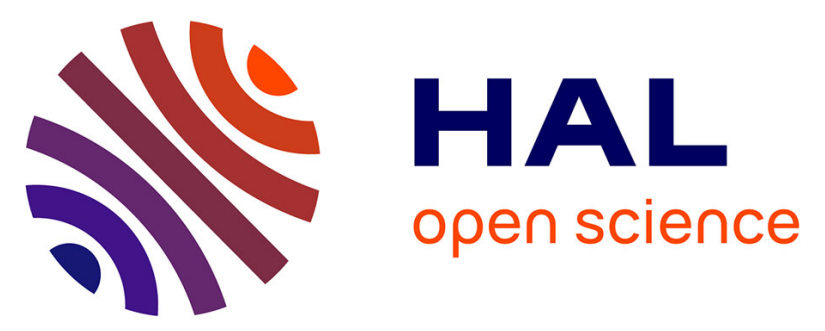

\title{
Copper and iron metabolism in Ostreococcus tauri - the role of phytotransferrin, plastocyanin and a chloroplast copper-transporting ATPase
}

Ivo Florin Scheiber, Jana Pilátová, Ronald Malych, Eva Kotabova, Matyáš Krijt, Daniel Vyoral, Jan Mach, Thibaut Léger, Jean-Michel Camadro, Ondřej Prášil, et al.

\section{To cite this version:}

Ivo Florin Scheiber, Jana Pilátová, Ronald Malych, Eva Kotabova, Matyáš Krijt, et al.. Copper and iron metabolism in Ostreococcus tauri - the role of phytotransferrin, plastocyanin and a chloroplast copper-transporting ATPase. Metallomics, 2019, 11 (10), pp.1657-1666. 10.1039/c9mt00078j . hal02351689

\section{HAL Id: hal-02351689 \\ https://hal.science/hal-02351689}

Submitted on 6 Nov 2019

HAL is a multi-disciplinary open access archive for the deposit and dissemination of scientific research documents, whether they are published or not. The documents may come from teaching and research institutions in France or abroad, or from public or private research centers.
L'archive ouverte pluridisciplinaire HAL, est destinée au dépôt et à la diffusion de documents scientifiques de niveau recherche, publiés ou non, émanant des établissements d'enseignement et de recherche français ou étrangers, des laboratoires publics ou privés. 


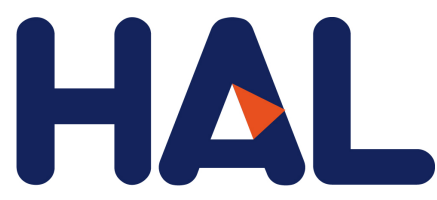

archives-ouvertes

\title{
Copper and iron metabolism in Ostreococcus tauri - the role of phytotransferrin, plastocyanin and a chloroplast copper-transporting ATPase
}

\author{
Ivo Florin Scheiber, Jana Pilátová, Ronald Malych, Eva Kotabova, Matyáš
}

Krijt, Daniel Vyoral, Jan Mach, Thibaut Léger, Jean-Michel Camadro, Ondřej

Prášil, et al.

\section{To cite this version:}

Ivo Florin Scheiber, Jana Pilátová, Ronald Malych, Eva Kotabova, Matyáš Krijt, et al.. Copper and iron metabolism in Ostreococcus tauri - the role of phytotransferrin, plastocyanin and a chloroplast copper-transporting ATPase. Metallomics, Royal Society of Chemistry, 2019, 11 (10), pp.1657-1666. $10.1039 / \mathrm{c} 9 \mathrm{mt} 00078 \mathrm{j}$. hal-02351689

\section{HAL Id: hal-02351689 \\ https://hal.archives-ouvertes.fr/hal-02351689}

Submitted on 6 Nov 2019

HAL is a multi-disciplinary open access archive for the deposit and dissemination of scientific research documents, whether they are published or not. The documents may come from teaching and research institutions in France or abroad, or from public or private research centers.
L'archive ouverte pluridisciplinaire HAL, est destinée au dépôt et à la diffusion de documents scientifiques de niveau recherche, publiés ou non, émanant des établissements d'enseignement et de recherche français ou étrangers, des laboratoires publics ou privés. 
Check for updates

Cite this: DOI: $10.1039 / c 9 m t 00078 j$

Received 3rd April 2019,

Accepted 15th July 2019

DOI: $10.1039 / c 9 m+00078$

rsc.li/metallomics

\section{Copper and iron metabolism in Ostreococcus} tauri - the role of phytotransferrin, plastocyanin and a chloroplast copper-transporting ATPase $\dagger$

\author{
Ivo Florin Scheiber, ${ }^{a b}$ Jana Pilátová, ${ }^{a}$ Ronald Malych, ${ }^{a}$ Eva Kotabova, ${ }^{c}$ Matyáš Krijt, \\ Daniel Vyoral, ${ }^{\text {de }}$ Jan Mach, ${ }^{a}$ Thibaut Léger, (D) ${ }^{f}$ Jean-Michel Camadro, \\ Ondřej Prášil, ${ }^{c}$ Emmanuel Lesuisse ${ }^{*^{f}}$ and Robert Sutak (D) *a
}

\begin{abstract}
Iron and copper are essential elements for practically all living organisms. Their metabolism is frequently interconnected, and while copper is relatively abundant in the ocean, iron is often a limiting factor for the growth of many marine microorganisms. In the present study, we aimed to elucidate the metabolisms of copper and iron and the connection of both in the marine picoalga Ostreococcus tauri. We show that $O$. tauri adjusts its copper economy in response to copper deficiency by downregulation of the expression of plastocyanin in favor of cytochrome $c$ oxidase without significant changes in growth and physiology. Copper deprivation leads to increased expression of copper transporting ATPase and proteins involved in tetrapyrrole synthesis, most likely to ensure higher turnover of chlorophyll and/ or heme. Elucidation of the effect of copper on the incorporation of iron into $O$. tauri proteins led us to identify the major iron uptake mediating protein, Ot-Fea1, whose expression and binding of iron is copper dependent. Based on our investigation of the incorporation of iron into Ot-Fea1 and ferritin, we hypothesize that $O$. tauri possesses another Fea1-independent iron uptake system.
\end{abstract}

Significance to metallomics

Marine microorganisms depend on a proper supply of both copper and iron to fulfill their metabolic functions. While the molecular mechanisms by which eukaryotic marine phytoplankton cope with iron deprivation have recently been discovered, our understanding of copper metabolism remains largely unknown in these ecologically important organisms. We believe that our multidisciplinary study (including biochemical, physiological, proteomic and protein separation techniques) will enhance our understanding of copper and iron homeostasis in marine microalgae as well as in plants.

\section{Introduction}

Analogous to other organisms, eukaryotic phytoplankton rely on copper as a cofactor for enzymes involved in vital processes such as respiration and oxidative defense. To ensure a sufficient supply of copper while preventing the toxicity of excess copper,

\footnotetext{
${ }^{a}$ Department of Parasitology, Faculty of Science, Charles University, BIOCEV, Vestec, Czech Republic.E-mail: sutak@natur.cuni.cz

${ }^{b}$ Department of Nutritional Sciences, The University of Arizona, Tucson, AZ 85721, USA

${ }^{c}$ Institute of Microbiology, Academy of Sciences, Centrum Algatech, Trebon, Czech Republic

${ }^{d}$ Institute of Hematology and Blood Transfusion, Prague, Czech Republic

${ }^{e}$ Institute of Pathological Physiology, First Faculty of Medicine, Charles University, Prague, Czech Republic

${ }^{f}$ CNRS, Institut Jacques Monod, Université Paris Diderot-Paris 7, Paris, France. E-mail: emmanuel.lesuisse@ijm.fr

$\dagger$ Electronic supplementary information (ESI) available. See DOI: 10.1039/c9mt00078j
}

microalgae have evolved complex mechanisms to regulate copper homeostasis. ${ }^{1}$ Most of the knowledge of copper transport in microalgae originates from the remarkable investigation of the freshwater alga Chlamydomonas reinhardtii, ${ }^{2,3}$ whereas little is known about the metabolism of copper in marine phytoplankton. However, genes that code for proteins known to be involved in copper metabolism have recently been identified in the genomes of marine microalgae. Homologues of the cellular copper transporter ctr1 seem to be present in all major groups. Copper-transporting ATPases and a copper-chaperone responsible for the delivery of copper to plastocyanin in the chloroplast are found in some species but are absent in others regardless of the presence of plastocyanin. ${ }^{1}$

As in terrestrial organisms, copper and iron metabolism are interconnected in freshwater and marine microalgae. Thus, C. reinhardtii utilizes a yeast-like reductive uptake system to meet its metabolic iron demands. ${ }^{4}$ Multicopper ferroxidases have also been suggested to be involved in iron uptake by some 
marine diatoms due to the presence of gene homology and transcriptomic analysis, and copper-dependent reductive uptake of iron has been demonstrated for Thalassiosira oceanica and Thalassiosira pseudonana. ${ }^{5}$ Moreover, some microalgae can lower their copper requirement in the event of copper limitation by replacing copper-containing plastocyanin with iron-containing cytochrome $c_{6}$ for the electron transport from the cytochrome $b_{6} f$ complex to PSI. ${ }^{1}$

To cope with the low-iron bioavailability in marine habitats, marine algae species not only aim to minimize their iron-quota but have also developed highly efficient iron uptake mechanisms. In addition to the copper-dependent reductive iron uptake mentioned above, different marine microalgae have been shown to take up iron by a nonreductive mechanism that involves a binding step at the cell surface. ${ }^{6,7}$ Iron-starvation induced protein (ISIP) $2 \mathrm{a}$ has been identified as a phytotransferrin responsible for binding ferric iron at the cell surface and subsequent endocytosis-mediated uptake in the pennate diatom Phaeodactylum tricornutum. ${ }^{8,9}$ A function in the uptake of siderophore-bound iron via endocytosis by diatoms has recently been ascribed to ISIP1. ${ }^{10}$

In recent years, the picoeukaryotic alga $O$. tauri has become a good model to study iron metabolism in marine eukaryotic phytoplankton because it is easy to cultivate and molecular tools to study its gene functions are available. ${ }^{11}$ We have recently shown that iron homeostasis is strongly controlled by the day/night cycle and that this regulation is orchestrated by ferritin via recycling of intracellular iron. ${ }^{12}$ Based on the transcriptomic and bioinformatics data, we have proposed that the components involved in iron acquisition in $O$. tauri are a ZIP-family protein (Ot-Irt1) and a new Fea1-related protein (Ot-Fea1), a homologue of phytotransferrin in P. tricornutum. ${ }^{13}$ Interestingly, Ostreococcus strains isolated from contrasted environments display different levels of adaptation to iron limitation, and the strain with the lowest iron requirements (RCC802) responds to iron deprivation by reduction of the photosynthetic machinery and cell biomass, rather than by cell size reduction. ${ }^{14}$

In the present study, we focused on the consequences of copper deprivation in $O$. tauri. Proteomic profiling revealed alterations in the expression of proteins involved in the metabolism of copper, iron and tetrapyrroles in response to copper limitation. Photosynthesis and iron acquisition in $O$. tauri were studied. Importantly, we identified Ot-Fea1 as the major iron binding protein in $O$. tauri, supporting the role of algal phytotransferrin-like proteins in iron acquisition.

\section{Results}

To investigate the effects of copper availability in $O$. tauri, we grew $O$. tauri cells for one week under either copper-sufficient or copper-deficient conditions. Copper limitation was achieved by the addition of $10 \mu \mathrm{M}$ of the specific copper chelator bathocuproine disulfonate (BCS) to the growth medium, whereas copper-sufficiency was ensured by adding $100 \mathrm{nM} \mathrm{CuSO}_{4}$. This concentration of copper exceeds the estimated copper concentration in the surface waters of the open ocean by several times ${ }^{15}$ and we have shown previously that it is sufficient to support maximal growth of $O$. tauri. $^{13}$

The growth of $O$. tauri did not differ significantly between the copper-limiting and copper-sufficient conditions (Fig. S1A-C, $\mathrm{ESI} \dagger$ ), but the cellular copper content of cells grown under copper limitation decreased to $9 \%$ of that contained in cells grown under copper sufficiency (Fig. S1D, ESI $\dagger$ ). Hence, our conditions are appropriate to study the effects of copper limitation without severely compromising the fitness of the cells. Considering that $O$. tauri lacks a homologue of cytochrome $c_{6}$ and thus, solely relies on copper-containing plastocyanin for the electron transport from the cytochrome $b_{6} f$ complex to $\mathrm{PSI},{ }^{16}$ these results demonstrate that $O$. tauri possesses efficient strategies to cope with copper limitation.

To gain an overview of the effect of copper availability on protein expression, we performed a label-free whole-cell proteomic analysis of copper-deficient cells compared to copper-sufficient cells. We identified 135 proteins whose expression was more than 2-fold upregulated upon copper starvation and 76 proteins that were downregulated (Table S1, ESI $\dagger$ ). Most of the regulated proteins are of unknown function or within the regulatory category (Fig. S2 and Table S1, ESI $\dagger$ ). The only copper-containing protein whose expression was significantly affected by copper availability was plastocyanin, which was lowered 2.68-fold. The lowered expression of plastocyanin and the unaltered expression of cytochrome $c$ oxidase in response to copper limitation was confirmed by immunoblot analysis (Fig. 1). Due to the absence of a homologue of cytochrome $c_{6}, O$. tauri solely relies on plastocyanin for the electron transport from the cytochrome $b_{6} f$ complex to PSI. ${ }^{16}$ Thus, the allocation of copper from plastocyanin to other copper-containing proteins upon copper depletion, as has been shown for cytochrome $c$ oxidase in $C$. reinhardtii, ${ }^{2}$ might account for the unaltered expression of these proteins in $O$. tauri.

A homologue of copper transporting P-type ATPase of Arabidopsis thaliana 1 (PAA1) that contained the characteristic metal binding and ion-transduction motifs (Fig. S4, ESI $\dagger$ ), was upregulated 2.11-fold upon copper limitation. In A. thaliana

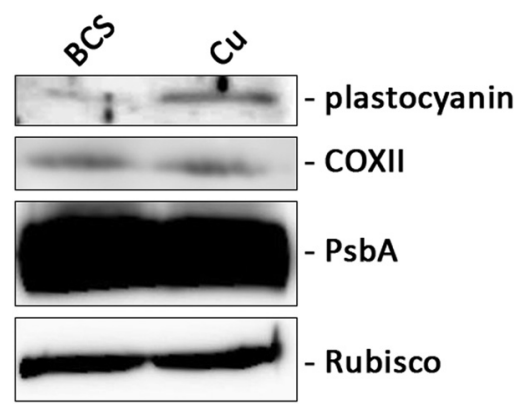

Fig. 1 Effect of copper availability on cytochrome $c$ oxidase subunit 2 and plastocyanin abundance. $O$. tauri cells were grown for 7 days in modified $\mathrm{f} / 2$ medium containing $1 \mathrm{nM}$ ferric citrate and either $10 \mu \mathrm{M}$ of the specific copper chelator BCS (BCS) or $100 \mathrm{nM} \mathrm{CuSO}_{4}(\mathrm{Cu})$. Whole-cell lysates were separated by SDS-PAGE before immunoblotting with antibodies specific for plastocyanin or cytochrome $c$ oxidase subunit 2. PsbA, RuBisCO and Coomassie blue staining (Fig. S2, ESI $\dagger$ ) were used to verify equal loading. 
PAA1 is critical for copper-delivery to stromal $\mathrm{Cu}, \mathrm{Zn}$-superoxide dismutase ( $\mathrm{Cu} / \mathrm{Zn}$ SOD) and, in concert with P-type ATPase of Arabidopsis 2 (PAA2), for copper-delivery to plastocyanin in the thylakoid lumen. ${ }^{18,19}$ Thus, this protein is likely to fulfill this function in $O$. tauri, and its overexpression in response to copper limitation is part of the adaptive response of $O$. tauri cells to such a condition.

In $C$. reinhardtii, three redox steps in the tetrapyrrole biosynthesis pathway are stimulated by copper, i.e., CPX1-coproporphyrinogen III oxidase, CRD1-Mg-protoporphyrin IX monomethyl ester cyclase, and CAO-chlorophyllide $a$ oxygenase.$^{20}$ Additionally, in $O$. tauri, four enzymes involved in tetrapyrrole metabolism were among the proteins whose expression was increased upon copper limitation: magnesium-protoporphyrin IX methyltransferase (ostta07g02590), uroporphyrinogen decarboxylase (ostta01g03390), porphobilinogen synthase (ostta01g02390) and pheophorbide $a$ oxygenase (ostta07g02450). Hence, we analyzed the effect of copper starvation on the heme and chlorophyll contents of $O$. tauri cells. However, while iron availability influenced the concentration of both heme and chlorophyll, neither of these tetrapyrroles was significantly affected by copper availability (Fig. S5, ESI†).

In $T$. oceanica, which like $O$. tauri utilizes plastocyanin as the sole electron carrier between the cytochrome $b_{6} f$ complex and PSI, the rate of electron transfer from the cytochrome $b_{6} f$ complex to PSI is decreased in Cu-limited cells. ${ }^{16,17}$ Hence, we investigated the consequences of the decreased expression of plastocyanin in copper-deprived $O$. tauri cells for several photosynthetic parameters. The rate of photosynthesis was determined by measurement of oxygen evolution and electron flux through PSII (Fig. 2A and B). The light response curves show slightly slower transfer of electrons via PSII in copperlimited cells, while the differences in oxygen production were not statistically significant. The quantum yields of both PSII and PSI (YII $=\mathrm{Fv} / \mathrm{Fm}$ and YI, resp.) were not affected by the absence of copper (Fig. 2C). This indicates that $O$. tauri cells grown under our copper-deficient conditions still contain sufficient holoplastocyanin to maintain normal photosynthesis.

We observed only little rearrangements in photosynthetic apparatus in response to copper limitation in our proteomic analysis (Fig. S2 and Table S1, ESI†). The most affected component of the photosynthetic apparatus was the PSI-G subunit of PSI that increased by 7.26-fold. For A. thaliana plants devoid of PSI-G a higher efficiency of PSI that correlated with higher affinity for binding of plastocyanin to PSI had been reported. ${ }^{21,22}$ Based on the function of PSI-G in A. thaliana, it may be inferred that under copper limitation $O$. tauri lowers the efficiency of electron transport from the cytochrome $b_{6} f$ complex to PSI. Considering the decrease in plastocyanin abundance under copper limitation this finding is surprising and requires further studies.

In our previous work, blue native electrophoresis of protein extracts from cells incubated with ${ }^{55} \mathrm{Fe}$ isotopes allowed us to identify ferritin as the major iron-containing protein in $O$. tauri. ${ }^{12}$ In the present study, we analyzed the effects of copper and iron limitation on the incorporation of ${ }^{55} \mathrm{Fe}$ into protein complexes. In iron-deprived cells grown under copper sufficiency, we discovered a band with a lower molecular weight whose iron content was
A

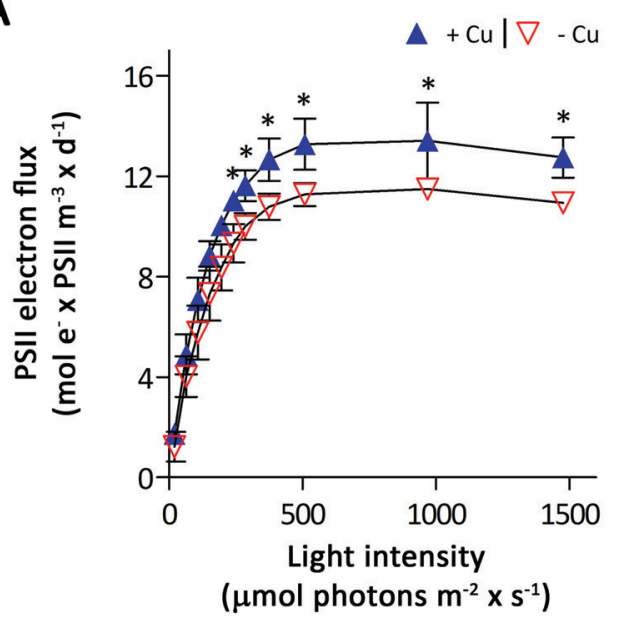

B

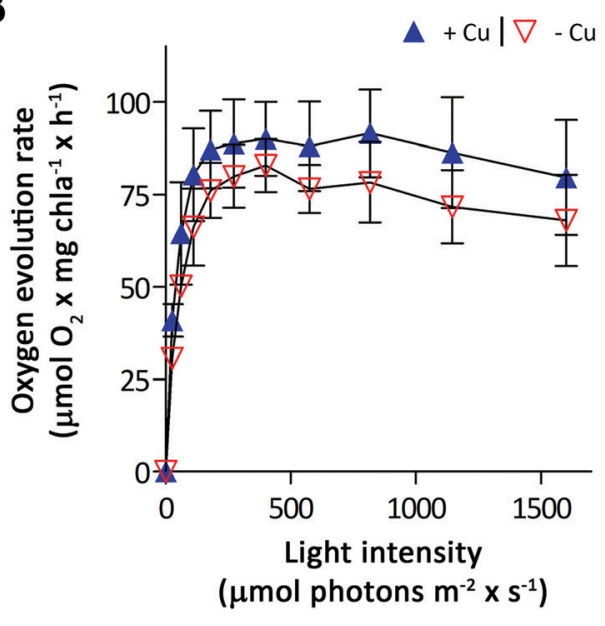

C

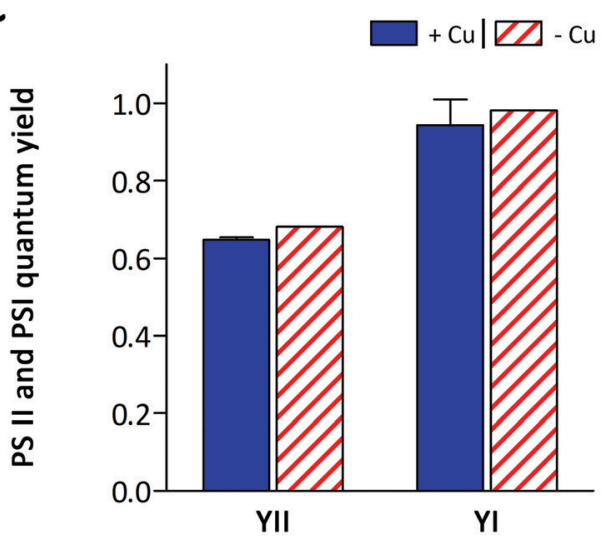

Fig. 2 Photosynthesis light response curves and quantum yields of photosystems II and I in 0 . tauri. $O$. tauri cells were grown for 7 days in modified f/2 medium containing $100 \mathrm{nM}$ ferric citrate and either $10 \mu \mathrm{M}$ of the specific copper chelator BCS (BCS) or $100 \mathrm{nM} \mathrm{CuSO}_{4}(\mathrm{Cu})$. (A) Photosynthetic oxygen evolution rate and (B) photosynthetic electron transport rate via photosystem II versus light intensity. (C) Maximal PSII quantum yield ( $\mathrm{YII}=\mathrm{Fv} / \mathrm{Fm}$ ) and photochemical quantum yield of $\mathrm{PSI}(\mathrm{YI})$. Data are presented as means \pm SD from 3 independent experiments. Statistical analysis was performed using a two-sample $t$-test with ${ }^{*} p<0.05$. 
A

$$
\frac{-\mathrm{Fe}}{c^{v} \mathrm{c}^{\mathrm{c}}} \frac{\mathrm{Fe}}{c^{v} \mathrm{c}^{\mathrm{c}}}
$$

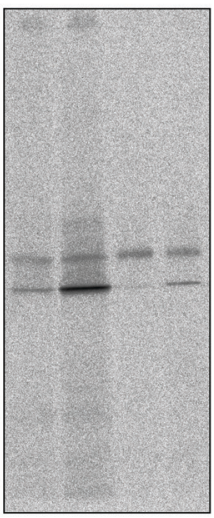

B

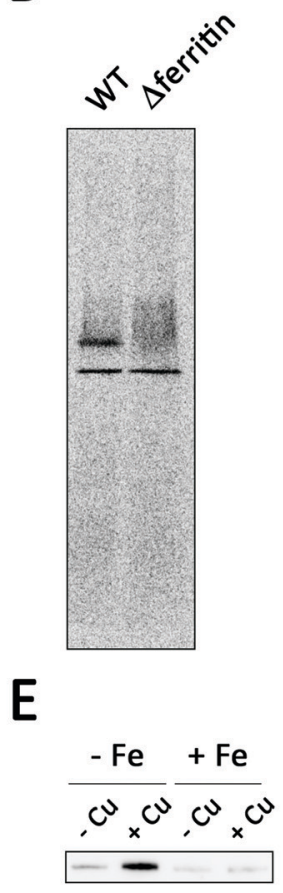

C

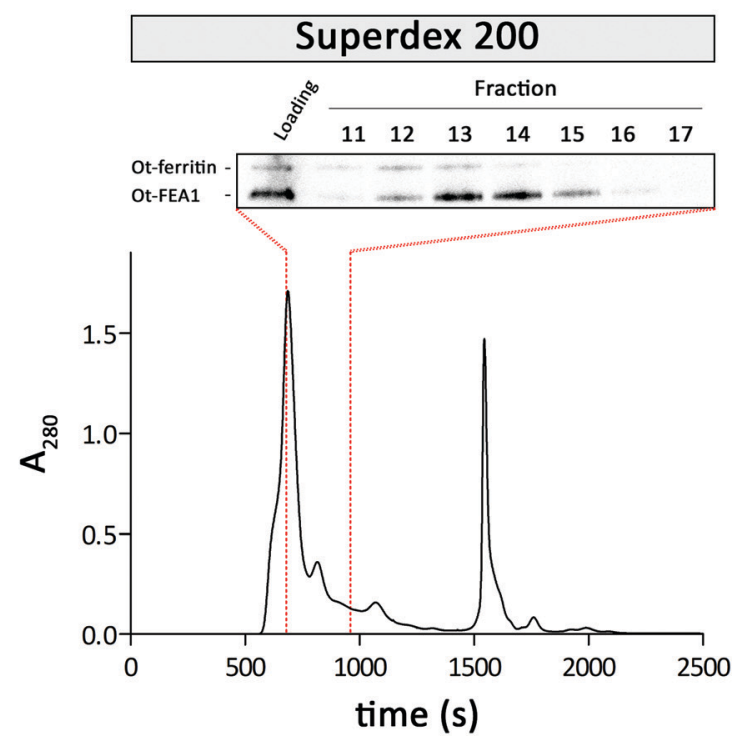

D

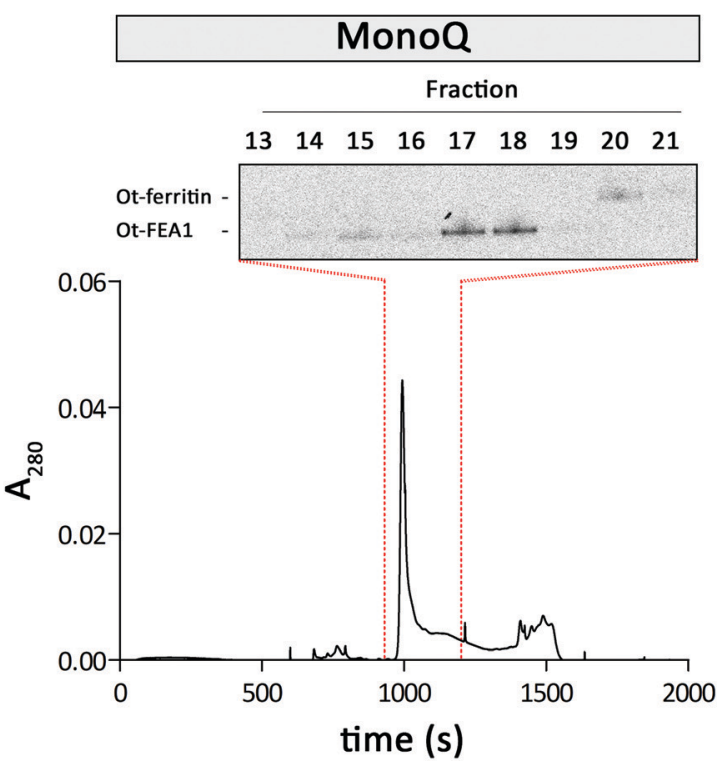

Fig. 3 Identification of the major iron-binding proteins in O. tauri. O. tauri cells were grown for 7 days in modified f/2 medium (A) containing $1 \mathrm{nM}$ ( - Fe) or $100 \mathrm{nM}(+\mathrm{Fe})$ ferric citrate and either $100 \mathrm{nM} \mathrm{CuSO}_{4}(+\mathrm{Cu})$ or $10 \mu \mathrm{M}$ of the specific copper chelator BCS $(-\mathrm{Cu})$. Cells were harvested and incubated for $2 \mathrm{~h}$ with $1 \mu \mathrm{M}{ }^{55} \mathrm{Fe}$-citrate. Equal amounts of protein were separated by (A) blue native electrophoresis and analyzed by autoradiography and (E) SDSPAGE before immunoblotting with anti Ot-Fea1 antibody. (B) $O$. tauri wild type (WT) or ferritin knock-out ( $\Delta$ ferritin) cells were grown with $100 \mathrm{nM}$ ferric citrate and $100 \mathrm{nM} \mathrm{CuSO}_{4}$. Cells were harvested and incubated for $2 \mathrm{~h}$ with $1 \mu \mathrm{M}^{55} \mathrm{Fe}$-citrate. Equal amounts of protein were separated by blue native electrophoresis and analyzed by autoradiography. (C \& D) Purification of the major iron-containing protein complex in iron-deficient and coppersufficient conditions. $O$. tauri cells were grown with $1 \mathrm{nM}$ ferric citrate and $100 \mathrm{nM} \mathrm{CuSO}$. Cells were harvested and incubated for $2 \mathrm{~h}$ with $1 \mu \mathrm{M}$ ${ }^{55} \mathrm{Fe}$-citrate. Following lysis, cell lysates were separated by gel filtration. (C) The fractions indicated in the figures were separated by blue native electrophoresis and analyzed by autoradiography. Fractions 13-15 were pooled and further separated on a MonoQ column. (D) Fractions 13-21 were separated by blue native electrophoresis and analyzed by autoradiography.

higher than that of ferritin, as judged by autoradiography of native gels (Fig. 3A and B). To identify this protein complex, we performed two subsequent liquid chromatography steps - size exclusion chromatography and ion-exchange chromatography - using blue native electrophoresis combined with autoradiography for detecting the iron-containing complexes (Fig. 3C and D). After the second chromatography step, fractions enriched in the major iron-containing band were separated in parallel via blue native electrophoresis and via native electrophoresis on gels containing 1.5\% Triton X-100. Both separation techniques have previously 
been shown to be nondissociative, allowing the identification of various iron-protein complexes. ${ }^{23}$ Bands containing ${ }^{55} \mathrm{Fe}$ were subsequently analyzed by mass spectrometry. Among the identified proteins, Ot-Fea1 was one of the proteins with the highest score (Table S2, ESI $\dagger$ ), establishing this protein as the major iron-binding protein in $O$. tauri. This result confirms our previous identification of Ot-Fea1 as one of the iron-binding complexes, ${ }^{13}$ and is consistent with the growing evidence that Fea1-domain-containing proteins play an important role in iron uptake by marine phytoplankton, including O. tauri. ${ }^{8,13}$ Confirming previous results ${ }^{13}$ Ot-Fea1 is induced upon iron starvation (Fig. 3E). However, in concomitant copper-limiting conditions the induction of Ot-Fea1 in response to iron limitation is severely impaired (Fig. 3E). Thus, the increased binding of iron to Ot-Fea1 in O. tauri cells grown under copperreplete conditions compared to copper-deficient cells reflects the higher expression of Ot-Fea1 in these cells.

Having identified the two major iron-binding proteins in O. tauri, Ot-Fea1 and ferritin, we next further characterized iron binding to these proteins employing native electrophoresis coupled with autoradiography. The time course of iron incorporation demonstrates that iron binding to Ot-Fea1 is more rapid than iron incorporation into ferritin (Fig. 4A), suggesting

A

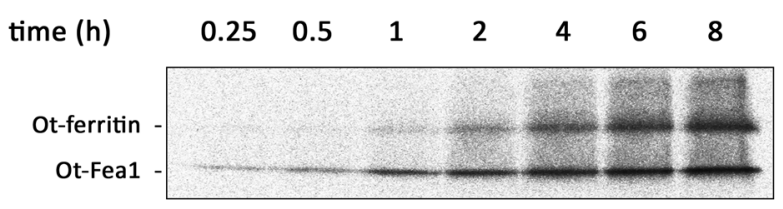

B

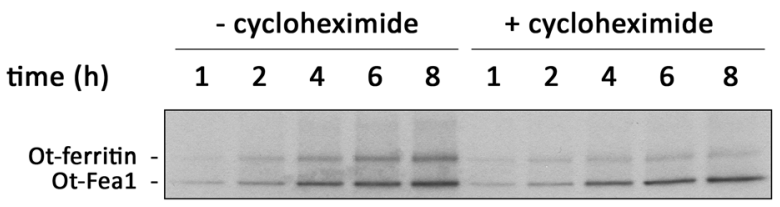

C

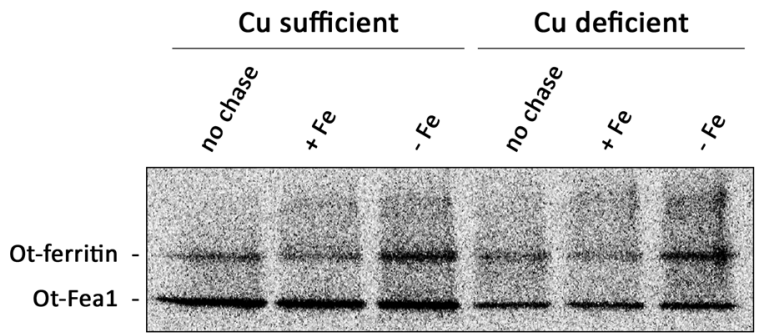

Fig. 4 Incorporation of ${ }^{55} \mathrm{Fe}$ into Ot-ferritin and Ot-Fea1. O. tauri cells were grown in modified $\mathrm{f} / 2$ medium containing $1 \mathrm{nM}$ ferric citrate and $100 \mathrm{nM} \mathrm{CuSO}$. (A) Time dependency of incorporation of ${ }^{55} \mathrm{Fe}$ into Ot-ferritin and Ot-Fea1 from $1 \mu \mathrm{M}^{55} \mathrm{Fe}$-citrate. (B) Consequence of inhibition of protein synthesis on incorporation of ${ }^{55} \mathrm{Fe}$ into Ot-ferritin and Ot-Fea1. Cells were incubated for up to $8 \mathrm{~h}$ with $1 \mu \mathrm{M}^{55} \mathrm{Fe}$-citrate in the presence or absence of $10 \mathrm{mg} \mathrm{mL}^{-1}$ of the protein synthesis inhibitor cycloheximide. (C) Pulse chase analysis of ${ }^{55} \mathrm{Fe}$ incorporation into Ot-ferritin and Ot-Fea1. O. tauri cells were incubated for $2 \mathrm{~h}$ with $1 \mu \mathrm{M}^{55} \mathrm{Fe}$-citrate, after which the cells were either collected for analysis or incubated for an additional $2 \mathrm{~h}$ in the presence or absence of $1 \mu \mathrm{M}$ Fe-citrate. Equal amounts of protein were separated by blue native electrophoresis and analyzed by autoradiography. that iron-binding to Ot-Fea1 precedes iron incorporation into ferritin. Experiments using cycloheximide revealed that unlike ferritin, which is induced when cellular iron contents increase, binding of iron to Ot-Fea1 is not affected by protein synthesis inhibition, indicating constitutive expression and low protein turnover of Ot-Fea1 in iron-deficient O. tauri cells (Fig. 4B). Pulse chase experiments showed that iron was not replaced from Ot-Fea1 after two hours, while iron turnover in ferritin was high (Fig. 4C). The high protein and iron turnover of ferritin reflects its principal role in the diel regulation of iron homeostasis. ${ }^{12}$ The efficient iron binding to Ot-Fea1, which is not affected by protein synthesis inhibitors or replaced in pulse chase experiments, is likely to correspond with the huge capacity of algal cells to acquire iron in a nutritionally poor environment with episodic iron enrichment events. ${ }^{8}$

To evaluate whether Ot-Fea1 levels correlate with a higher capacity for iron accumulation, we next determined ${ }^{55} \mathrm{Fe}$ uptake by $O$. tauri cells grown under iron-replete/-deficient and copperreplete/-deficient conditions. In line with previous reports, ${ }^{6,13,24}$ O. tauri cells grown under iron limitation accumulated more ${ }^{55} \mathrm{Fe}$ than cells grown under iron-replete conditions. In contrast, copper availability did not affect ${ }^{55} \mathrm{Fe}$-accumulation by $O$. tauri cells (Fig. 5). Consistent with this finding the decreased binding of iron to Ot-Fea1 in copper-deficient $O$. tauri cells compared to copperreplete $O$. tauri cells is not reflected in the subsequent incorporation of iron into ferritin (Fig. 3A and 4C). The lack of a correlation between iron-binding to Ot-Fea1 and cellular iron accumulation strongly suggests the existence of Ot-Fea1-independent iron uptake pathways in $O$. tauri.

\section{Discussion}

In the present study, we investigated the effects of copper deprivation on protein expression and iron metabolism in the marine microalgae $O$. tauri. We demonstrated that $O$. tauri possesses effective strategies to thrive in severe copper limitation. Moreover, we identified Ot-Fea1 as a copper-regulated protein, establishing a new iron-copper connection in O. tauri. O. tauri relies on copper-containing plastocyanin for the electron transport from the cytochrome $b_{6} f$ complex to PSI since it lacks a homologue of cytochrome $c_{6}$ as an alternative electron carrier, ${ }^{16}$ and, thus, must have efficient mechanisms in place to sustain growth in the copper-limited environment of the open ocean. Indeed, growth rates are not affected in growth medium extremely low in copper, not even in the presence of $10 \mu \mathrm{M}$ of the strong copper chelator BCS.

We did not detect the putative copper transporter ostta04g03950 (homologous to the A. thaliana COPT2) in our proteomic data, the only protein in the genome of $O$. tauri that contains the signature motifs of the copper transporter family. ${ }^{25}$ This could reflect a low expression level of this protein, the high resistance of membrane proteins to tryptic digestion, or both. However, our proteomic analysis revealed that copper-deficient O. tauri utilizes a copper-sparing and -redistributing strategy to cope with copper deficiency. 

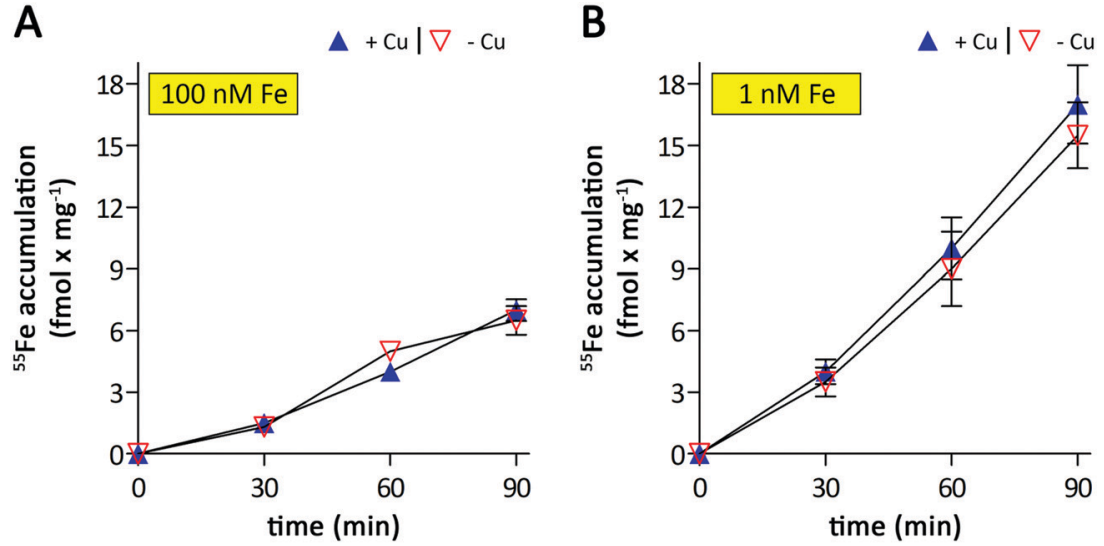

Fig. 5 Effect of copper on iron uptake by $O$. tauri. $O$. tauri cells were grown for 7 days in modified $\mathrm{f} / 2$ medium containing either $10 \mu \mathrm{M}$ of the specific copper chelator BCS $(-\mathrm{Cu})$ or $100 \mathrm{nM} \mathrm{CuSO}_{4}(+\mathrm{Cu})$ and (A) $100 \mathrm{nM}$ or (B) $1 \mathrm{nM}$ ferric citrate. The cells were harvested and incubated with $1 \mu \mathrm{M}^{55} \mathrm{Fe}(\mathrm{III})-$ EDTA for up to 90 minutes. Data are presented as means \pm SD from 3 independent experiments. Statistical analysis was performed using two-way ANOVA.

Upon copper deprivation, $O$. tauri cells decrease the expression of plastocyanin while maintaining the expression levels of the copper-containing subunit of cytochrome $c$ oxidase and $\mathrm{Cu} /$ Zn SOD. A similar effect was described in C. reinhardtii. ${ }^{2}$ Copper limitation in this freshwater algae leads to enhanced proteolytic degradation and replacement of copper-containing plastocyanin by heme-containing cytochrome $c_{6}$, to ensure the copper demand for cytochrome $c$ oxidase. $^{2}$ In contrast to C. reinhardtii, cytochrome $c_{6}$ is missing in $O$. tauri ${ }^{16}$ The only cytochrome $c_{6}$-like protein contained in the $O$. tauri genome contains a loop insertion peptide typical for plant cytochrome $c_{6} a$ (Fig. S7, ESI $\dagger$ ) that, due to its low redox potential, cannot function as an effective electron carrier between the cytochrome $b_{6} f$ complex and PSI. ${ }^{26}$ Moreover, the expression of this protein in O. tauri is rather low, ${ }^{13}$ and we did not identify it in our proteomic data from copper-deprived cells. Thus, plastocyanin seems to be the only protein that can accept electrons from the cytochrome $b_{6} f$ complex in $O$. tauri.

The marine diatom Thalassiosira oceanica uses, similar to o. tauri, plastocyanin instead of cytochrome $c_{6}$ in the photosynthetic electron transport chain. ${ }^{17}$ Recently, differences in the response to copper limitation were reported for two $T$. oceanica strains. ${ }^{27}$ T. oceanica strain CCMP1003 responded to copper limitation with a decrease in plastocyanin expression, and concomitant rearrangements in the photosynthetic apparatus resulting in a shift from photochemistry to photoprotection. In contrast, T. oceanica strain CCMP1005 kept plastocyanin levels stable upon copper deprivation, but decreased its growth rate, cell size, chlorophyll $a$, and total protein content. In $O$. tauri, the growth rate and chlorophyll $a$ content were not altered upon copper limitation, but the plastocyanin levels decreased. However, these were not accompanied by profound changes in photosynthetic parameters as was the case for $T$. oceanica strain CCMP1003. We argue that, besides functioning as an electron carrier between the cytochrome $b_{6} f$ complex and PSI, plastocyanin acts as a site of copper storage that can be allocated to cytochrome $c$ oxidase, $\mathrm{Cu} / \mathrm{Zn} \mathrm{SOD}$, and other copper proteins when copper becomes limiting, as has been suggested for C. reinhardtii. ${ }^{2}$ Such alternative function is supported by the recent finding that plastocyanin improves oxidative stress tolerance by regulating copper homeostasis under stress conditions. ${ }^{28}$

Copper has to be shuttled efficiently from the cytosol into the chloroplast to ensure metalation of stromal $\mathrm{Cu} / \mathrm{Zn} \mathrm{SOD}$ and luminal plastocyanin. ${ }^{29}$ This becomes even more important under copper deficiency, when distributable copper in the cytosol is sparse. $O$. tauri may comply with this requirement by increasing the abundance of ostta11g02300 (homologous to PAA1). In contrast, no regulation on transcript or protein level has been observed in response to copper availability for Arabidopsis PAA1, ${ }^{29}$ but PAA2 appears to be regulated at the post-translational level. ${ }^{30}$ The molecular mechanisms underlying the regulation of ostta11g02300 in O. tauri remain to be elucidated. We did not identify a homologue of $C$. reinhardtii copper-sensing transcription factor CRR1 in the genome of $O$. tauri, and the GTAC core sequence of the copper response element identified in C. reinhardtii ${ }^{20}$ is not present in the upstream region of this $O$. tauri $\mathrm{Cu}$-transporting ATPase.

In A. thaliana, the function of $\mathrm{Cu} / \mathrm{Zn}$ SOD is substituted by Fe SOD in conditions of copper deprivation..$^{19}$ We did not observe a significant decrease in the expression of $\mathrm{Cu} / \mathrm{Zn} \mathrm{SOD}$, and we did not detect changes in Mn or Ni SOD. The subcellular localization of SODs varies among algal taxa, ${ }^{31}$ and it is probable that these enzymes are present in different cellular compartments in $O$. tauri; thus, the activity of the cuproenzyme cannot be replaced.

The overexpression of several proteins participating in tetrapyrrole synthesis upon copper limitation did not result in changes in chlorophyll and heme cellular levels. However, we postulate that these changes are accompanied by increased turnover of chlorophyll. Continuous pigment turnover despite their constant steady-state levels or nonstressful light was observed in Arabidopsis leaves. ${ }^{32}$ The importance of tetrapyrrole turnover in $O$. tauri was recently demonstrated by the circadian regulation of genes involved in tetrapyrrole metabolism, and diurnal 
changes in the cellular content of chlorophyll and heme. ${ }^{13}$ Increased turnover of tetrapyrroles in copper-limited O. tauri may ensure higher efficiency of the photosystem to compensate for lower, albeit sufficient, levels of plastocyanin and/or other copper-dependent proteins or pathways not identified in this study. An effect of copper deficiency on the upregulation of the tetrapyrrole pathway has also been described in Chlamydomonas, but the physiological significance of these changes has not been elucidated. ${ }^{20}$

Using different separation techniques, we identified the major iron binding protein under iron-limited and coppersufficient conditions in $O$. tauri as Ot-Fea1. In our previous work, we hypothesized that this novel protein mediates iron acquisition in $O$. tauri cells. ${ }^{13}$ In the present study, we provide direct evidence of iron binding to Ot-Fea1. Moreover, our characterization of iron binding to protein complexes in $O$. tauri demonstrates that Ot-Fea1 is the first protein that binds iron when added to iron-deficient cells that have been grown under copper-replete conditions, providing further evidence for a role of Ot-Fea1 in iron acquisition. Such a function would agree with the recent identification of Fea1-domain-containing proteins as phytotransferrins. ${ }^{9}$ Considering the wide distribution of Fea1-related proteins in marine algal species, our results highlight the importance of these proteins in phytoplankton iron acquisition.

Confirming previous reports, ${ }^{13}$ the expression of Ot-Fea1 and, most likely as a direct consequence, the binding of iron to Fea1 were induced by iron starvation. We have previously shown that the addition of $100 \mathrm{nM}$ copper to iron-deficient growth medium caused a slight further increase of Ot-Fea1-levels. ${ }^{13}$ Consistent with this observation, O. tauri fails to increase Ot-Fea1-levels and ironbinding when grown under copper-limiting conditions.

In $C$. reinhardtii, iron uptake is $\mathrm{Cu}$-dependent because the reoxidation of iron during its uptake is catalyzed by a multicopper ferroxidase. ${ }^{4,33}$ In contrast, $O$. tauri lacks such a clear ironcopper connection. ${ }^{13}$ While the acquisition of iron is induced by iron starvation, as is the binding of iron to Ot-Fea1, iron uptake is not altered in response to varying levels of copper in the growth medium. Consistent with the latter observation, iron incorporation into ferritin was not affected by $\mathrm{Cu}$ limitation, yet we observed a decrease in Ot-Fea1 expression and consequent iron binding to this protein. Moreover, in our pulse-chase experiments, ${ }^{55} \mathrm{Fe}$ was not redistributed from Ot-Fea1 to other iron-containing proteins in the chase period, indicating that binding of iron to Ot-Fea1 does not reflect its subsequent use by the cell. Taken together, these findings strongly suggest the existence of an Ot-Fea1-independent iron uptake pathway in O. tauri.

In summary, we have demonstrated that $O$. tauri is able to adapt to extremely low copper levels. Our data highlight the role of Ot-Fea1 in iron uptake and identifies Ot-Fea1 as a copper-regulated protein, thus establishing a new iron-copper connection present in $O$. tauri. Moreover, our data suggest the existence of an additional, Fea1-independent iron uptake mechanism, though the molecular components of this iron acquisition pathway remain to be identified. The presented technical approach for directly observing binding of iron to Ot-Fea1 and incorporation into ferritin is a new tool for studying different cell lines mutated in candidate genes involved in iron acquisition machinery.

\section{Materials \& methods}

\section{Cell culture}

O. tauri was grown at $20{ }^{\circ} \mathrm{C}$ under a $12 \mathrm{~h} / 12 \mathrm{~h}$ light $\left(50 \mu \mathrm{mol} \mathrm{m}^{-2} \mathrm{~s}^{-1}\right) /$ dark regime in a modified $\mathrm{f} / 2$ medium, as described previously. ${ }^{13}$ For maintenance of the culture, iron was added as $100 \mathrm{nM}$ ferric citrate $(1: 20)$. Iron-deficiency was induced by shifting the cells to growth medium containing only $1 \mathrm{nM}$ ferric citrate $(1: 20)$. To study the effects of copper on $O$. tauri, either $100 \mathrm{nM} \mathrm{CuSO}_{4}$ (copper-sufficient condition) or $10 \mu \mathrm{M}$ of BCS (copper-deficient condition) was added to the media. Cell growth was assessed by flow cytometry using a MACSQuant ${ }^{\circledR}$ Analyzer 10 (Miltenyi Biotec, Bergisch Gladbach, Germany). If not stated otherwise, $O$. tauri cells were grown for 7 days in the growth media specified in the legends of the figures and harvested for experiments at the beginning of the light period.

\section{Mass spectrometry analyses}

Whole cell proteins were extracted by sonication in SDS loading buffer on ice and subsequently run on a $4-12 \%$ acrylamide gel (Invitrogen, Carsbad, CA, USA) and stained in SimplyBlue SafeStain (Invitrogen). Three gel plugs representing the total migration $(5 \mathrm{~mm})$ of each sample were cut for each condition. Proteins from plugs were reduced with $10 \mathrm{mM}$ DTT, alkylated with $55 \mathrm{mM}$ iodoacetamide (IAA) and incubated with $20 \mu \mathrm{l}$ of $25 \mathrm{mM} \mathrm{NH} \mathrm{HCO}_{3}$ containing $12.5 \mu \mathrm{g} \mathrm{ml}{ }^{-1}$ sequencing-grade trypsin (Promega, Madison, Wi, USA) overnight at $37{ }^{\circ} \mathrm{C}$. Digests were pooled according to each sample and analyzed using an LTQ Velos Orbitrap (Thermo Fisher Scientific, San Jose, CA) instrument coupled to an Easy nano-LC Proxeon 1000 system (Thermo Fisher Scientific). Chromatographic separation of peptides was performed with the following parameters: Acclaim Pepmap100 precolumn ( $5 \mathrm{~mm}, 300 \mu$ mi.d., C18, $5 \mu \mathrm{m}$, and $100 \AA$ ) and Easy Column Proxeon C18 (50 cm, $75 \mu \mathrm{m}$ i.d., and $120 \AA$ ), $300 \mathrm{nl} \mathrm{min}^{-1}$ flow, gradient rising from 95\% solvent A (water $-0.1 \%$ formic acid) to $35 \%$ B $(100 \%$ acetonitrile, and $0.1 \%$ formic acid) over $97 \mathrm{~min}$, then to $80 \%$ B over $6 \mathrm{~min}$ for a total run time of $118 \mathrm{~min}$. Peptides were analyzed in the Orbitrap cell in full ion scan mode at a resolution of 30000 (at $\mathrm{m} / \mathrm{z} 400$ ) and a mass range of $400-1800 \mathrm{~m} / \mathrm{z}$. Fragments were obtained with a collision-induced dissociation (CID) activation with a collisional energy of $40 \%$, an activation $Q$ of 0.25 for $10 \mathrm{~ms}$, and analyzed in the LTQ. MS/MS data were acquired in a data-dependent mode in which 20 of the most intense precursor ions were isolated, with a dynamic exclusion of 20 seconds and an exclusion mass width of $10 \mathrm{ppm}$.

\section{Peptide and protein identifications and quantifications.}

Label-free relative quantification (XIC) was performed between subjects analysed using the Progenesis-Qi software 4.0 (Nonlinear Dynamics Ltd, Newcastle, UK). For the identification step, all MS 
and MS/MS data were processed with the Mascot search engine (Matrix Science, version 2.5.1). The mass tolerance was set to $7 \mathrm{ppm}$ for precursor ions and 0.5 Da for fragments. The following modifications were used for variable parameters: oxidation (M), phosphorylation (Ser, Thr, and Tyr), carbamidomethylation (Cys), deamidation (Asn, and Gln), and acetylation (N-term, and Lys). The maximum number of missed cleavages was limited to 2 for trypsin digestion. An O. tauri protein database (2014) was used for the identification step. Peptides with a Mascot score above 15 were considered. Protein abundance measurements were calculated according to the Hi-3 label-free quantification method. Protein variations were validated if their calculated $p$-values were below 0.05 .

Blue native PAGE. Cells were washed, transferred to fresh medium without added iron or copper and incubated with $1 \mu \mathrm{M}{ }^{55} \mathrm{Fe}$-citrate $(1: 20)$ as specified in the figures and figure legends. Iron uptake was stopped by the addition of a mixture of iron chelators $(0.1 \mathrm{mM}$ bathophenanthroline disulfonate, $0.1 \mathrm{mM}$ desferrioxamine B, and $5 \mathrm{mM}$ EDTA; final concentrations). Subsequently, the cells were washed and disrupted by sonication in the presence of $0.7 \%$ digitonin, and proteins were separated using the Novex Native PAGE Bis-Tris Gel system (4-16\%; Invitrogen). Following electrophoresis, the gels were vacuumdried and autoradiographed using a BAS-IP TR 2025 E tritium storage phosphor screen (GE Healthcare Life Sciences, Chicago, IL, USA) or X-ray film.

\section{Western blot analysis}

Whole cell lysates were prepared as described previously. ${ }^{13}$ Immunoblot analysis was performed as described previously. ${ }^{13}$ The rabbit anti-Ot-Fea1 polyclonal antibody raised against the peptide CTKYEFPKTRASGNY was generated and purified by GenScript (Nanjing, Jiangsu Province, China). The rabbit antiplastocyanin antibody (AS06 118), rabbit anti-Rubisco large subunit, form I and form II antibodies (AS03 037), rabbit antiPsbA (AS05 084) and rabbit anti-cytochrome oxidase subunit II antibody (AS04 053A) were from Agrisera (Vännäs, Sweden).

\section{Purification and identification of the iron-binding protein complex}

Cells were harvested and transferred to fresh medium without added iron and incubated with $1 \mu \mathrm{M}{ }^{55} \mathrm{Fe}$-citrate $(1: 20)$ for $2 \mathrm{~h}$. The cells were then washed to remove extracellular iron and disrupted by sonication in $10 \mathrm{mM}$ HEPES ( $\mathrm{pH} 7.5)$ in the presence of $1 \%$ digitonin. Cell lysate was loaded onto a size exclusion chromatography column (Superdex ${ }^{\mathrm{TM}} 200$ Increase 10/300 GL) and separated in $50 \mathrm{mM}$ HEPES (pH 7.5) using a BioLogic DuoFlow ${ }^{\mathrm{TM}}$ medium-pressure chromatography system (Bio-Rad, Hercules, CA, USA). The obtained $0.5 \mathrm{ml}$ fractions were analyzed by blue native electrophoresis, and fractions containing significant signals of the main unknown radioactive band were combined and loaded onto the anion exchange chromatography column (Mono $\mathrm{Q}^{\mathrm{TM}}$ 5/50 GL). After washing the column with $50 \mathrm{mM}$ HEPES ( $\mathrm{pH} 7.5$ ), bound proteins were eluted with a linear gradient of $1 \mathrm{M} \mathrm{NaOH}$. Then, $0.5 \mathrm{ml}$ fractions were analyzed by BN-PAGE. Fractions containing the main unknown band were then separated on a linear gradient (3-20\%) polyacrylamide gel in the presence of the nonionic detergent Triton X-100. ${ }^{23}$ Both gels (BN-PAGE and Triton X-100 PAGE) were dried and autoradiographed using X-ray film. The radioactive bands of $c a .1 \times 5 \mathrm{~mm}$ were excised and rehydrated for $2 \mathrm{~h}$ in $50 \%$ acetonitrile and $50 \mathrm{mM} \mathrm{NH}_{4} \mathrm{HCO}_{3}$, the filter paper was removed, and the proteins were cleaved as described previously. ${ }^{34}$ Peptides were analyzed on an Orbitrap Fusion system as described previously. ${ }^{35}$ Proteins were identified with the Proteome Discoverer 1.4 software using a search against the ORCAE database. ${ }^{36}$

\section{${ }^{55}$ Fe uptake}

Iron uptake rates were measured in $2 \mathrm{ml}$ micro-centrifuge tubes as previously described. ${ }^{13}$ The assay was started by addition of $1 \mu \mathrm{M}$ ferric EDTA $(1: 20)$ and stopped with a mixture of strong iron chelators $(0.1 \mathrm{mM}$ bathophenanthroline disulfonate, $0.1 \mathrm{mM}$ desferrioxamine B, and $5 \mathrm{mM}$ EDTA; final concentrations). The cells were then washed three times with washing buffer (EDTA/ oxalate), and counted in a Wallac $1450 \mu$ Beta TriLux scintillation counter. To prevent quenching, cell pigments were bleached with sodium hypochlorite before scintillation counting.

\section{Other methods}

Chlorophyll $a$ content was determined spectrophotometrically as described in Lelandais et al. ${ }^{13}$ (based on Porra et al. ${ }^{37}$ ).

Heme $b$ was quantified by HPLC as previously described in Lelandais et $a l .^{13}$ (based on Pyrih et al. ${ }^{38}$ ).

ICP-MS analyses were performed by Dr R. Lobinski, Laboratoire de Chimie Analytique Bioinorganique et Environnement, CNRS/UPPA, Pau, France. ${ }^{39}$

Photosynthetic oxygen evolution was measured using a Hansatech DW1 oxygen electrode chamber (Hansatech Instruments Ltd, Narborough, UK) coupled to a PSI OxyCorder 401 A/D signal transducer equipped with the PSI OxyWin software (Photon Systems Instruments, Brno, Czech Republic). Oxygen evolution was measured in the presence of $1 \mathrm{mM}$ sodium bicarbonate under eleven different light intensities, ranging from 0 to $1600 \mu \mathrm{mol}$ photons $\mathrm{m}^{-2} \mathrm{~s}^{-1}$. The light intensities were attained using LEDs of the Act2 Systems (Chelsea Technologies Group Ltd, Surrey, UK). The presented values are calculated from the slope of $\mathrm{O}_{2}$ evolution at a given irradiance plus the slope of respiratory $\mathrm{O}_{2}$ utilization measured in the dark.

Photosynthetic electron flux via photosystem II was estimated by fast repetition rate fluorometry using a FastOcean (Chelsea Technologies Group Ltd) system using a single turnover induction protocol of 100 blue and orange (450 and $624 \mathrm{~nm}$ ) flashlets over ca. $200 \mu \mathrm{s}$ ( $2 \mu \mathrm{s}$ flashlet pitch). This was done for the 11 levels of actinic light intensities (0-1476 $\mu \mathrm{mol}$ photons $\left.\mathrm{m}^{-2} \mathrm{~s}^{-1}\right)$. Data were then fitted using FastPRO software (Chelsea Technologies Group).

Quantum yields of photosystems II and I were measured using the saturation pulse method by a Dual-PAM-100 system (Walz, Effeltrich, Germany). Before the measurement, the cell culture was $10 \times$ concentrated by centrifugation and dark adapted for $10 \mathrm{~min}$. Centrifugation had no effect on cell viability. 


\section{Author contributions}

Robert Sutak, Emmanuel Lesuisse, and Ivo Florin Scheiber conception and design of the experiments. Thibaut Léger, and Jean-Michel Camadro - proteomics measurements. Matyáš Krijt, and Daniel Vyoral - native separation of proteins. Ondřej Prášil, and Eva Kotabova - assessment of photosynthetic parameters. Jana Pilátová, Ronald Malych, Jan Mach, and Ivo Florin Scheiber - performed other experiments. Ivo Florin Scheiber, Robert Sutak, and Emmanuel Lesuisse - writing of the publication.

\section{Conflicts of interest}

There are no conflicts to declare.

\section{Acknowledgements}

This work was supported by the Czech Science Foundation (1807822S), Agence Nationale de la Recherche (ANR-16-CE01-0008 "Phytomet"), Project for Conceptual Development of Research Organizations (00023736) of the Czech Ministry of Health, LO 1416 (NPU I) Algatech plus and LQ1604 NPU II provided by Ministry of Education, Youth and Sports of the Czech Republic (MEYS), CZ.02.1.01/0.0/0.0/16_019/0000759 CePaViP provided by The European Regional Development Fund and MEYS, and MiCoBion project funded from EU H2020 (No 810224). We thank Dr R. Lobinski for performing ICP-MS analyses and Dr F. Y. Bouget for providing the ferritin knock-out strain.

\section{References}

1 C. E. Blaby-Haas and S. S. Merchant, Regulating cellular trace metal economy in algae, Curr. Opin. Plant Biol., 2017, 39, 88-96.

2 J. Kropat, S. D. Gallaher, E. I. Urzica, S. S. Nakamoto, D. Strenkert, S. Tottey, A. Z. Mason and S. S. Merchant, Copper economy in Chlamydomonas: Prioritized allocation and reallocation of copper to respiration vs. photosynthesis, Proc. Natl. Acad. Sci. U. S. A., 2015, 112, 2644-2651.

3 C. E. Blaby-Haas and S. S. Merchant, The ins and outs of algal metal transport, Biochim. Biophys. Acta, Mol. Cell Res., 2012, 1823, 1531-1552.

4 S. La Fontaine, J. M. Quinn, S. S. Nakamoto, M. D. Page, V. Gohre, J. L. Mosely, J. Kropat and S. Merchant, Copperdependent iron assimilation pathway in the model photosynthetic eukaryote Chlamydomonas reinhardtii, Eukaryotic Cell, 2002, 1, 736-757.

5 M. T. Maldonado, A. E. Allen, J. S. Chong, K. Lin, D. Leus, N. Karpenko and S. L. Harris, Copper-dependent iron transport in coastal and oceanic diatoms, Limnol. Oceanogr., 2006, 51, 1729-1743.

6 R. Sutak, H. Botebol, P. L. Blaiseau, T. Leger, F. Y. Bouget, J. M. Camadro and E. Lesuisse, A Comparative Study of Iron Uptake Mechanisms in Marine Microalgae: Iron Binding at the Cell Surface Is a Critical Step, Plant Physiol., 2012, 160, 2271-2284.

7 R. Sutak, J. Slapeta, M. San Roman, J. M. Camadro and E. Lesuisse, Nonreductive Iron Uptake Mechanism in the Marine Alveolate Chromera velia, Plant Physiol., 2010, 154, 991-1000.

8 J. Morrissey, R. Sutak, J. Paz-Yepes, A. Tanaka, A. Moustafa, A. Veluchamy, Y. Thomas, H. Botebol, F. Y. Bouget, J. B. McQuaid, L. Tirichine, A. E. Allen, E. Lesuisse and C. Bowler, A Novel Protein, Ubiquitous in Marine Phytoplankton, Concentrates Iron at the Cell Surface and Facilitates Uptake, Curr. Biol., 2015, 25, 364-371.

9 J. B. McQuaid, A. B. Kustka, M. Obornik, A. Horak, J. R. McCrow, B. J. Karas, H. Zheng, T. Kindeberg, A. J. Andersson, K. A. Barbeau and A. E. Allen, Carbonate-sensitive phytotransferrin controls high-affinity iron uptake in diatoms, Nature, 2018, 555, 534-537.

10 E. Kazamia, R. Sutak, J. Paz-Yepes, R. G. Dorrell, F. R. J. Vieira, J. Mach, J. Morrissey, S. Leon, F. Lam, E. Pelletier, J. M. Camadro, C. Bowler and E. Lesuisse, Endocytosismediated siderophore uptake as a strategy for Fe acquisition in diatoms, Sci. Adv., 2018, 4, eaar4536.

11 J. C. Lozano, P. Schatt, H. Botebol, V. Verge, E. Lesuisse, S. Blain, I. A. Carre and F. Y. Bouget, Efficient gene targeting and removal of foreign DNA by homologous recombination in the picoeukaryote Ostreococcus, Plant J., 2014, 78, 1073-1083.

12 H. Botebol, E. Lesuisse, R. Sutak, C. Six, J. C. Lozano, P. Schatt, V. Verge, A. Kirilovsky, J. Morrissey, T. Leger, J. M. Camadro, A. Gueneugues, C. Bowler, S. Blain and F. Y. Bouget, Central role for ferritin in the day/night regulation of iron homeostasis in marine phytoplankton, Proc. Natl. Acad. Sci. U. S. A., 2015, 112, 14652-14657.

13 G. Lelandais, I. Scheiber, J. Paz-Yepes, J. C. Lozano, H. Botebol, J. Pilatova, V. Zarsky, T. Leger, P. L. Blaiseau, C. Bowler, F. Y. Bouget, J. M. Camadro, R. Sutak and E. Lesuisse, Ostreococcus tauri is a new model green alga for studying iron metabolism in eukaryotic phytoplankton, BMC Genomics, 2016, 17, 319.

14 H. Botebol, G. Lelandais, C. Six, E. Lesuisse, A. Meng, L. Bittner, S. Lecrom, R. Sutak, J. C. Lozano, P. Schatt, V. Verge, S. Blain and F. Y. Bouget, Acclimation of a low iron adapted Ostreococcus strain to iron limitation through cell biomass lowering, Sci. Rep., 2017, 7, 327.

15 K. W. Bruland and M. C. Lohan, Controls of Trace Metals in Seawater, Elsevier-Pergamon, Oxford, 2003.

16 B. Palenik, J. Grimwood, A. Aerts, P. Rouze, A. Salamov, N. Putnam, C. Dupont, R. Jorgensen, E. Derelle, S. Rombauts, K. M. Zhou, R. Otillar, S. S. Merchant, S. Podell, T. Gaasterland, C. Napoli, K. Gendler, A. Manuell, V. Tai, O. Vallon, G. Piganeau, S. Jancek, M. Heijde, K. Jabbari, C. Bowler, M. Lohr, S. Robbens, G. Werner, I. Dubchak, G. J. Pazour, Q. H. Ren, I. Paulsen, C. Delwiche, J. Schmutz, D. Rokhsar, Y. Van de Peer, H. Moreau and I. V. Grigoriev, The tiny eukaryote Ostreococcus provides genomic insights into the paradox of plankton speciation, Proc. Natl. Acad. Sci. U. S. A., 2007, 104, 7705-7710. 
17 G. Peers and N. M. Price, Copper-containing plastocyanin used for electron transport by an oceanic diatom, Nature, 2006, 441, 341-344.

18 T. Shikanai, P. Muller-Moule, Y. Munekage, K. K. Niyogi and M. Pilon, PAA1, a P-type ATPase of Arabidopsis, functions in copper transport in chloroplasts, Plant Cell, 2003, 15, 1333-1346.

19 S. E. Abdel-Ghany, P. Muller-Moule, K. K. Niyogi, M. Pilon and T. Shikanai, Two P-type ATPases are required for copper delivery in Arabidopsis thaliana chloroplasts, Plant Cell, 2005, 17, 1233-1251.

20 M. Castruita, D. Casero, S. J. Karpowicz, J. Kropat, A. Vieler, S. I. Hsieh, W. H. Yan, S. Cokus, J. A. Loo, C. Benning, M. Pellegrini and S. S. Merchant, Systems Biology Approach in Chlamydomonas Reveals Connections between Copper Nutrition and Multiple Metabolic Steps, Plant Cell, 2011, 23, 1273-1292.

21 P. E. Jensen, L. Rosgaard, J. Knoetzel and H. V. Scheller, Photosystem I activity is increased in the absence of the PSI-G subunit, J. Biol. Chem., 2002, 277, 2798-2803.

22 A. Zygadlo, P. E. Jensen, D. Leister and H. V. Scheller, Photosystem I lacking the PSI-G subunit has a higher affinity for plastocyanin and is sensitive to photodamage, Biochim. Biophys. Acta, 2005, 1708, 154-163.

23 D. Vyoral and J. Petrak, Iron transport in K562 cells: a kinetic study using native gel electrophoresis and Fe-59 autoradiography, Biochim. Biophys. Acta, Mol. Cell Res., 1998, 1403, 179-188.

24 H. Botebol, R. Sutak, I. F. Scheiber, P. L. Blaiseau, F. Y. Bouget, J. M. Camadro and E. Lesuisse, Different iron sources to study the physiology and biochemistry of iron metabolism in marine micro-algae, Biometals, 2014, 27, 75-88.

25 M. J. Petris, The SLC31 (Ctr) copper transporter family, Pflugers Arch, 2004, 447, 752-755.

26 J. A. R. Worrall, B. G. Schlarb-Ridley, T. Reda, M. J. Marcaida, R. J. Moorlen, J. Wastl, J. Hirst, D. S. Bendall, B. F. Luisi and C. J. Howe, Modulation of heme redox potential in the cytochrome $c(6)$ family, J. Am. Chem. Soc., 2007, 129, 9468-9475.

27 A. A. Hippmann, N. Schuback, K. M. Moon, J. P. McCrow, A. E. Allen, L. J. Foster, B. R. Green and M. T. Maldonado, Contrasting effects of copper limitation on the photosynthetic apparatus in two strains of the open ocean diatom Thalassiosira oceanica, PLoS One, 2017, 12, e0181753.
28 X. T. Zhou, F. Wang, Y. P. Ma, L. J. Jia, N. Liu, H. Y. Wang, P. Zhao, G. X. Xia and N. Q. Zhong, Ectopic expression of SsPETE2, a plastocyanin from Suaeda salsa, improves plant tolerance to oxidative stress, Plant Sci., 2018, 268, 1-10.

29 G. Aguirre and M. Pilon, Copper Delivery to Chloroplast Proteins and its Regulation, Front. Plant Sci., 2015, 6, 1250.

30 W. Tapken, K. Ravet and M. Pilon, Plastocyanin Controls the Stabilization of the Thylakoid Cu-transporting P-type ATPase PAA2/HMA8 in Response to Low Copper in Arabidopsis, J. Biol. Chem., 2012, 287, 18544-18550.

31 F. Wolfe-Simon, D. Grzebyk, O. Schofield and P. G. Falkowski, The role and evolution of superoxide dismutases in algae, J. Phycol., 2005, 41, 453-465.

32 K. G. Beisel, S. Jahnke, D. Hofmann, S. Koppchen, U. Schurr and S. Matsubara, Continuous turnover of carotenes and chlorophyll a in mature leaves of Arabidopsis revealed by $14 \mathrm{CO} 2$ pulse-chase labeling, Plant Physiol., 2010, 152, 2188-2199.

33 A. Herbik, C. Bolling and T. J. Buckhout, The involvement of a multicopper oxidase in iron uptake by the green algae Chlamydomonas reinhardtii, Plant Physiol., 2002, 130, 2039-2048.

34 A. Shevchenko, H. Tomas, J. Havlis, J. V. Olsen and M. Mann, In-gel digestion for mass spectrometric characterization of proteins and proteomes, Nat. Protoc., 2006, 1, 2856-2860.

35 J. Mach, J. Bila, K. Zeniskova, D. Arbon, R. Malych, M. Glavanakovova, E. Nyvltova and R. Sutak, Iron economy in Naegleria gruberi reflects its metabolic flexibility, Int. J. Parasitol., 2018, 48, 719-727.

36 L. Sterck, K. Billiau, T. Abeel, P. Rouze and Y. van de Peer, ORCAE: online resource for community annotation of eukaryotes, Nat. Methods, 2012, 9, 1041.

37 R. J. Porra, W. A. Thompson and P. E. Kriedemann, Determination of Accurate Extinction Coefficients and SimultaneousEquations for Assaying Chlorophyll-a and Chlorophyll-B Extracted with 4 Different Solvents - Verification of the Concentration of Chlorophyll Standards by Atomic-Absorption Spectroscopy, Biochim. Biophys. Acta, 1989, 975, 384-394.

38 J. Pyrih, K. Harant, E. Martincova, R. Sutak, E. Lesuisse, I. Hrdy and J. Tachezy, Giardia intestinalis Incorporates Heme into Cytosolic Cytochrome b(5), Eukaryotic Cell, 2014, 13, 231-239.

39 M. Aoun, C. Arnaudguilhem, O. El Samad, R. B. Khozam and R. Lobinski, Impact of a phosphate fertilizer plant on the contamination of marine biota by heavy elements, Environ. Sci. Pollut. Res., 2015, 22, 14940-14949. 